\title{
Kinematic and electromyographic analyses of a karate punch
}

\author{
António M. VencesBrito ${ }^{\mathrm{a}, *}$, Mário A. Rodrigues Ferreira ${ }^{\mathrm{a}}$, Nelson Cortes ${ }^{\mathrm{b}}$, Orlando Fernandes ${ }^{\mathrm{c}}$, \\ Pedro Pezarat-Correia ${ }^{\mathrm{d}}$ \\ ${ }^{a}$ Sports Sciences School of Rio Maior, Polytechnic Institute of Santarém, Rio Maior, Portugal \\ ${ }^{\mathrm{b}}$ Sports Medicine Assessment Research and Testing Laboratory, School of Recreation, Health, and Tourism, George Mason University, Manassas, Virginia, USA \\ ' Sport and Health Department, Évora University, Évora, Portugal \\ ${ }^{\mathrm{d}}$ Faculty of Human Kinetics, Technical University of Lisbon, Lisbon, Portugal
}

\section{A R T I C L E I N F O}

\section{Article history:}

Received 24 June 2011

Received in revised form 14 September 2011

Accepted 14 September 2011

Available online $\mathrm{xxxx}$

\section{Keywords:}

Kinesiology

Electromyography

Motor control

Karate

Combat sports

\begin{abstract}
A B S T R A C T
The aims of this study were: (i) to present the kinematic and electromyographic patterns of the chokuzuki punch performed by 18 experienced karatekas from the Portuguese team, and (ii) to compare it with the execution of 19 participants without any karate experience. The kinematic and electromyographic data were collected from the arm and forearm during the execution of the specific punch. A two-way analysis of variance (ANOVA) was used with significant level set at $p \leqslant 0.05$. We found that the kinematic and neuromuscular activity in this punch occurs within $400 \mathrm{~ms}$. Muscle activities and kinematic analysis presented a sequence of activation bracing a near-distal end, with the arm muscles showing greater intensity of activation than muscles in the forearm. In the skill performance, the arm, flexion and internal rotation, and the forearm extension and pronation movements were executed with smaller amplitude in the karate group. Based on the results of this study, the two groups' presented distinct kinematic and electromyographic patterns during the performance of the choku-zuki punch.
\end{abstract}

(c) 2011 Elsevier Ltd. All rights reserved.

\section{Introduction}

In karate initiation training process the first and most simple punch to learn is the direct back forward punch focused at the middle chest, done in a static position (heikô-dachi). This form is known as choku-zuki and from him the karate athletes learned more complex forms of punching in static way and in movement (oi-zukiorgyaku-zuki). This learning evaluated from slowly and controlled movements into faster and potent movements against a target. So this is a fundamental skill in the training process of karate and its correct learning cold conduct to a increasing in performance and in an improvement in the prevention of impact injuries in the anatomical structures of the upper limb, which is especially important in the development of young karate subjects.

The choku-zuki is an example of a ballistic action when trying to reach a target as fast as possible, where the short movement duration can impose serious limitations to proprioceptive and visual correction. Those movements are centrally programmed and done accordingly a generated neuromuscular coordination patterns related with the task aim (Hallett et al., 1975; Sanes and Jennings,

* Corresponding author. Address: Escola Superior de Desporto de Rio Maior, Av. Dr. Mário Soares - Pavilhão Multiusos, 2040-413 Rio Maior, Portugal. Tel.: +351 243999280 .

E-mail address: abrito@esdrm.ipsantarem.pt (A.M. VencesBrito).
1984). Its performance requires a joint action sequence with the participation of the pelvis, torso, and upper arm, allowing use of energy that flows from the pelvis to the fist. The movement begins with rotation of the pelvis and continues with arm flexion, immediately followed by forearm extension. In this proximal-to-distal sequence is not clear the timing of the superior limb movements around the longitudinal axis, such as arm internal rotation and forearm pronation. Furthermore, besides empiric approaches (Nakayama, 1983; Courtonne, 1996; Link and Chou, 2011), there are no scientific literature studies to provide evidence on the kinematic and electromyography (EMG) characterization of the choku-zuki or to confirm the empiric acknowledgement.

Most assessments of segmental sequencing in throwing, tennis serves, striking or kicking has indicated a proximal-to-distal sequence, including for example joint angular velocities or end-point linear speeds (Van Gheluwe and Hebbelink, 1985; Putnam, 1993). However, it appears that the proximal-to-distal sequencing may be inadequate to accurately describe some complex movements as overhead throwing. In fact, the longitudinal axis rotations, arm internal rotation and forearm pronation, occur later in the movement and are the final components of the motion pattern. Some studies focused on the kinematic structure of different arm tasks show a decrease on movement duration and range during learning (Hobart et al., 1978; Jaegers et al., 1989; Pezarat-Correia et al., 2001). To our knowledge, this has not been identified in the choku-zuki task in karate. 
Electromyography analysis has showed a reduction in total myoelectric activity with practice in the laboratory (Engelhorn, 1983; Corcos et al., 1990) and during throwing tasks. Specifically, a decrease in the contraction time and time to maximum peak of agonist muscles (Miyashita et al., 1980; Jaegers et al., 1989; Pezarat-Correia et al., 2001). The decrease in antagonist latency was also found in throwing tasks (Hobart et al., 1978; Corcos et al., 1990). But in karate we do not know what really happens, we only empirically know that a powerful karate technique results from the momentum generated by the movement of several parts of the body, seeking that the maximum speed of the distal extremity (hand) is reached in the time of contact with the target. This results from a strong muscular contraction, which generates high force in very short time.

All of this depends of motor learning strategies that result in alterations in the internal processes that determine an individual capacity to produce a motor action after practice (Schmidt and Wrisberg, 2000). The EMG recording of muscle activation patterns during motor skill performance, allows measuring and characterizing muscles activity, as well as the intermuscular coordination patterns (Basmajian and De Luca, 1985). The identification of kinematic and EMG patterns inexperienced athletes can characterize the skill patterns and neuromuscular coordination developed with training. Thus, this characterization could be an important factor to the karate coach to define teaching strategies that leads to better performance, to avoid learning mistakes and prevent possible injuries that occurs with some frequency in the upper extremities (Zetaruk et al., 2005; Bledsoe et al., 2006; Zetaruk et al., 2000).

Therefore, the purpose of this study was to (i) characterize the kinematic and EMG patterns of the choku-zuki punch performed by experienced karatekas, and (ii) to compare the kinematic and EMG patterns of the choku-zuki punch between experienced karatekas and a control group (no karate experience). We hypothesized that kinematic and EMG patterns are different between karatekas and the control group.

\section{Method}

\subsection{Participants}

Two groups participated in the study; one composed 10 men and 8 women from the Portuguese karate team, all black belts with mean practice of 15 years and more than 4 years of national and international competitive experience, and a control group of 9 men and 10 women without previous experience in karate. All participants signed an informed consent document approved by the Faculty of Human Kinetics, Technical University of Lisbon ethical committee. The demographics of the two groups are shown in Table 1.

\subsection{Experimental design}

The study focused on the kinesiology analysis of a karate punching movement (choku-zuki) on a fixed target (makiwara) performed by the karate group (K) and the control group (NK). The makiwara, a wood board of $1.5 \mathrm{~cm}$ thickness and $134 \mathrm{~cm}$ length, was placed vertically and fixed on the ground, with the other end free. The target area was placed at a height of $116 \mathrm{~cm}$ from the ground and made of soft material.

The punch was accomplished by all participants starting from astatic position; standing facing to the makiwara at a distance of the upper limb length. The right upper limb was positioned with the arm extended at the shoulder joint less than $40^{\circ}$, and at the
Table 1

Physical characterization of the participants.

\begin{tabular}{llc}
\hline & Karate group & Non-karate \\
\hline Age (years) & $26.1 \pm 4.6$ & $25.1 \pm 4.1$ \\
Height $(\mathrm{cm})$ & $169 \pm 9$ & $166 \pm 10$ \\
Weight $(\mathrm{kg})$ & $65.8 \pm 10.5$ & $63.2 \pm 11$ \\
Arm length $(\mathrm{cm})$ & $74.9 \pm 5$ & $72.6 \pm 5.4$ \\
Body fat $(\%)$ & $19.6 \pm 7.5$ & $20.4 \pm 6.3$ \\
\hline
\end{tabular}

Values are means \pm SD.

No statistically significant differences were found between groups $(p \leqslant .05)$.

elbow joint the forearm was flexed at approximately $90^{\circ}$, in supination with fist closed and placed on the iliac crest. From this position, they perform a fast punch until the fist contacts the target area of the makiwara (Fig. 1). Each subject performed 20 repetitions of the choku-zuki divided in four series of five punches, with a rest period of $5 \mathrm{~s}$ between repetition and $5 \mathrm{~min}$ between series.

\subsection{Apparatus}

Four electromagnetic sensors placed on the chest over the first thoracic vertebra, in the middle of the arm and externally, in the posterior face of the forearm near the fist, and in the makiwara $20 \mathrm{~cm}$ below the target. The sensors were connected to an extended range transmitter with a registration area of approximately $2.50 \mathrm{~m}$ of ray. They obtain kinematic data with a sampling frequency of $100 \mathrm{~Hz}$ ("Flock of Birds2" System Ascension Technology, Software - Motion Monitor version 6.05). After calibration (Meskers et al., 1999), the system presented a accuracy of $0.3 \mathrm{~mm}$ to the position and $0.15^{\circ}$ to the orientation.

EMG signals were recorded through surface-active bipolar electrodes (1992-2002 National Instruments, Frankfurt, Germany), with an input impedance of $10 \mathrm{G} \Omega$, noise of $1 \mu \mathrm{V}$, common mode rejection ratio (CMRR) of $120 \mathrm{db}$, and gain of 2500 . The electrodes were fixed on disposable detection surfaces (Medicoelectronics - Copenhagen, Denmark), self-adhesive with $\mathrm{Ag} / \mathrm{AgCl}$, with the centers separated $20 \mathrm{~mm}$ of distance. After skin preparation, electrodes were placed in the middle of each muscular belly in a longitudinal orientation. The ground electrode was placed on the fifth lumbar vertebra. The EMG record was collected, together with kinematic signals, through a 12-bits A/D converter (DaqCard ${ }^{\mathrm{TM}}-700$, Multifunction I/ 0 from National Instruments) with a sampling rate of $1600 \mathrm{~Hz}$. Acquisition was carried out using the DasyLab 6.0 (Biovision). The EMG signal processing was performed with custom made software developed in MATLAB ${ }^{\circledR}$ (The Mathworks Inc, Natick Massachusetts, USA).

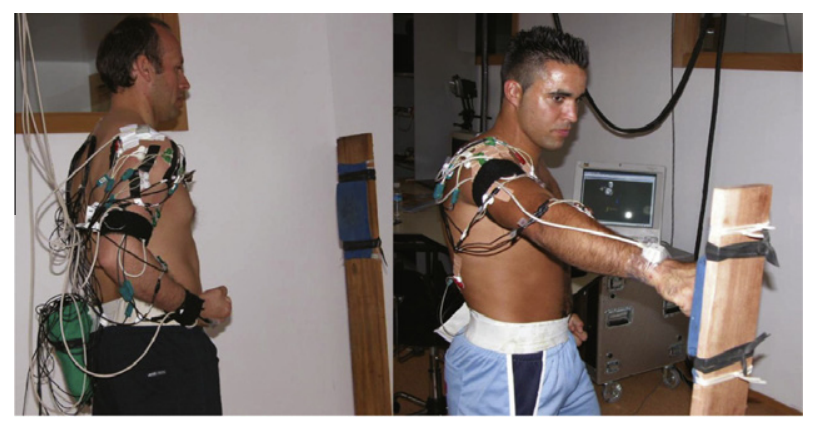

Fig. 1. Illustration of experimental setup showing the subject starts position facing to the makiwara and prepared to perform the punch, and final position of the movement with the fist in contact with the target. 


\subsection{Data reduction}

\subsubsection{Kinematic}

Participants were previously calibrated for the electromagnetic field created by the Flock of Birds2 (FOB), setting up the local system of coordinates of the arm and forearm in relation to the global system of coordinates. In this process the subjects were positioned according the descriptive anatomical standing but with the forearm in semipronation. This position defines the body planes (sagittal, frontal and transverse) and it's respectively axes of rotation (lateral, anteroposterior and longitudinal or vertical).

This procedure defines the positional zeros in the segments and serve of normalization process of the subject who permit the comparison between subjects. The glenohumeral joint center of rotation was determined using a kinematic estimation based on the calculation of instantaneous helical axes, and a geometric estimation based on a spherical fit through the surface of the glenoide (Meskers et al., 1998; Veeger, 2000).

The dual Euler angles approach was applied to maximize the accuracy, on computation of a three-dimensional shoulder joint motion with respect to the axes of the moving segment coordinate system (Ying and Kim, 2002).

The kinematic collected signals by the FOB from the arm flexion and internal rotation, and forearm extension and pronation movements were processed in MATLAB. A 2nd order low pass filter Butterworth of $10 \mathrm{~Hz}$ was applied to the kinematic data. Kinematic dependent variables consisted of: time of beginning and end of movement, duration, angle, speed, acceleration and respective peaks, measured from the initial static position until the impact time (Fig. 1).

The identification of the onset/offset of movement was visually performed on the MatLab output, by a single investigator trained for this purpose, and registered automatically, continuing the further data processing.

The angular speed and acceleration has been calculated directly by the software (Motion Monitor version 6.05) using the segments position data to calculate by derivation of the position the speed and acceleration.

\subsection{2. $E M G$}

Surface EMG was recorded from anterior (DA) and posterior (DP) portions of deltoid, clavicular (PC) and sternal (PS) portions of pectoralis major, infraespinatus (IF), biceps brachii (BB), brachioradialis (BR), lateral head of the triceps brachii $(\mathrm{TB})$ and pronator teres (PT).

Raw EMG signals were digitally filtered $(10-400 \mathrm{~Hz})$, full wave rectified and smoothed with a low pass filter of $50 \mathrm{~Hz}$ (Butterworth, 4th order). EMG signals were normalized using EMG signals from an isometric maximal voluntary contraction (IMVC) as a reference. Three different trials for IMVC were performed for each isolated muscle, with 1-min rest between trials. The trials were collected with the segments positioned in that each muscle has an intervention as preferential agonist developing its maximal intensity of activation, according to recommendations of Basmajin and De Luca (1985).

The EMG bursts were isolated on each trial to access time and amplitude parameters. The muscles BB, BR and PT showed two different activations in the choku-zuki performance, analyzed and referenced as first (BB1, BR1, and PT1) and second (BB2, BR2, and PT2) activation periods. (see Fig. 2).

In the normalized, rectified and smoothed EMG, the dependent variables studied were the onset and offset muscles activation time, EMG root mean square (RMS) between onset and offset of muscle activity and the time of peak EMG were measured and analyzed.
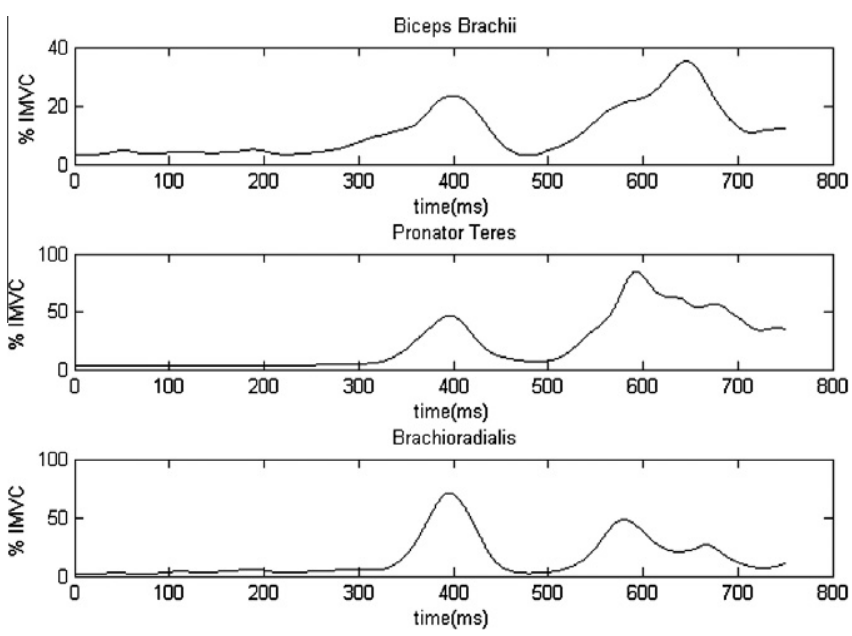

Fig. 2. Illustration of the two curves in the EMG of the BB, PT and BR muscles in the choku-zuki execution.

The determination of the onset/offset of muscles activation was made from the identification of an average value of activity, calculated on a time interval of $250 \mathrm{~ms}$ at the beginning of muscle activity record. The average activity calculated over three times the standard deviation was considered as a threshold intensity that once attained and maintained for $25 \mathrm{~ms}$ identified the time of onset/offset of the EMG pulse (Hodges and Bui, 1996; Giakas and Baltzopoulos, 1997; Micera et al., 1998; Roetenberg et al., 2003).

The EMG and kinematic data were synchronized by a simultaneous trigger input signal in the kinematic and EMG files and by the input of the FOB sensor placed on the makiwara that identify the time of contact, which was the final time of the movement and analysis.

\subsection{Statistics}

Descriptive data are presented as means and standard deviations.

To examine the differences between the two groups (independent variables - karate and non-karate) in the mean value for the kinematic and EMG dependent variables, the Kolmogorov-Smirnov test for normality, the Levene's test of homogeneity of variances and the one-way analysis of variance (ANOVA) was conducted. Alpha level was set a prior at 0.05 . Statistical analysis was performed with SPSS for Windows.

\section{Results}

\subsection{Kinematic description and comparison}

Table 2 presents the dependent kinematic variables on the karate and non-karate groups, as well as the significant differences.

According with the Table 2, the kinematic sequence of the segmental movements in the execution of the choku-zuki performed by the karatekas, begins with the forearm pronation and arm flexion movements in 242 and $237 \mathrm{~ms}$ before contact, respectively, followed then by the arm internal rotation and forearm extension, who began about 160 and $110 \mathrm{~ms}$ before contact, respectively. (see Fig. 3).

The arm flexion beganfrom extension at $-33^{\circ}$ and had mean range of $65^{\circ}$; was accelerated for about $190 \mathrm{~ms}$ and was the first to reach the peak angular speed about $50 \mathrm{~ms}$ before contact. Forearm pronation presented an range of about $40^{\circ}$ from the supination, accelerating during approximately $220 \mathrm{~ms}$ and performing 
Table 2

Mean and standard deviation of the kinematic variables in karate group (K) and non karate group (NK).

\begin{tabular}{|c|c|c|c|c|c|}
\hline & & \multicolumn{2}{|l|}{ Arm } & \multicolumn{2}{|l|}{ Forearm } \\
\hline & & Internal rotation & Flexion & Extension & Pronation \\
\hline \multirow[t]{2}{*}{ Initial angle } & $\mathrm{K}$ & $-29.3 \pm 12.3$ & $-33.3 \pm 6.9$ & $132 \pm 9.5$ & $-52.1 \pm 18.7$ \\
\hline & NK & $-31.5 \pm 12.7$ & $-34.3 \pm 1.5$ & $129.8 \pm 16.3$ & $-57.9 \pm 15.6$ \\
\hline \multirow[t]{2}{*}{ Contact angle } & $\mathrm{K}$ & $-11.7 \pm 16$ & $32.5 \pm 18$ & $75.2 \pm 19.8$ & $-10.26 \pm 16.1$ \\
\hline & NK & $-7.1 \pm 13.9$ & $37.9 \pm 15$ & $69 \pm 19.7$ & $9 \pm 17.6$ \\
\hline \multirow[t]{2}{*}{ Range angle } & $\mathrm{K}$ & $17.5 \pm 12.4$ & $65.8 \pm 16$ & $56.8 \pm 20$ & $41.8 \pm 16.2$ \\
\hline & NK & $24.4 \pm 12.3^{\mathrm{a}}$ & $72.2 \pm 15^{\mathrm{a}}$ & $60.8 \pm 19.2$ & $66.9 \pm 22.8^{\mathrm{a}}$ \\
\hline \multirow[t]{2}{*}{ Time between onset and contact } & $\mathrm{K}$ & $161 \pm 9$ & $237 \pm 65$ & $112 \pm 42$ & $242 \pm 91$ \\
\hline & NK & $176 \pm 53$ & $200 \pm 48^{\mathrm{a}}$ & $150 \pm 63^{a}$ & $348 \pm 7^{\mathrm{a}}$ \\
\hline \multirow[t]{2}{*}{ Peak angular speed } & $\mathrm{K}$ & $10.8 \pm 1.8$ & $2.9 \pm 1.8$ & $8.9 \pm 1.9$ & $3.87 \pm 2$ \\
\hline & NK & $10.1 \pm 2.2$ & $2.9 \pm 1.6$ & $8.8 \pm 2.1$ & $2.6 \pm 1.5^{\mathrm{a}}$ \\
\hline \multirow[t]{2}{*}{ Peak angular acceleration } & $\mathrm{K}$ & $0.9 \pm 0.6$ & $2.7 \pm 2.1$ & $0.7 \pm 0.65$ & $1.4 \pm 1.3$ \\
\hline & NK & $1 \pm 0.5$ & $3.2 \pm 1.5$ & $0.9 \pm 0.42$ & $2.7 \pm 1.5^{\mathrm{a}}$ \\
\hline \multirow[t]{2}{*}{ Time of peak angular speed } & $\mathrm{K}$ & $41 \pm 30$ & $50 \pm 38$ & $29 \pm 16$ & $20 \pm 36$ \\
\hline & NK & $42 \pm 22$ & $63 \pm 44$ & $46 \pm 29^{a}$ & $81 \pm 10^{\mathrm{a}}$ \\
\hline \multirow[t]{2}{*}{ Time of peak angular acceleration } & K & $69 \pm 55$ & $139 \pm 56$ & $61 \pm 41$ & $105 \pm 7$ \\
\hline & NK & $67 \pm 29$ & $132 \pm 49$ & $77 \pm 36$ & $207 \pm 10^{\mathrm{a}}$ \\
\hline \multirow[t]{2}{*}{ Duration of angular acceleration } & $\mathrm{K}$ & $119 \pm 87$ & $187 \pm 74$ & $83 \pm 37$ & $222 \pm 87$ \\
\hline & NK & $134 \pm 47$ & $137 \pm 59^{\mathrm{a}}$ & $104 \pm 44^{\mathrm{a}}$ & $267 \pm 90^{\mathrm{a}}$ \\
\hline
\end{tabular}

Angle - degree; time - millisecond; angular speed - rad.s ${ }^{-1}$; angular acceleration - rad. $\mathrm{s}^{-2}$.

${ }^{a}$ Indicates statistically significant differences between groups $(p \leqslant .05)$.
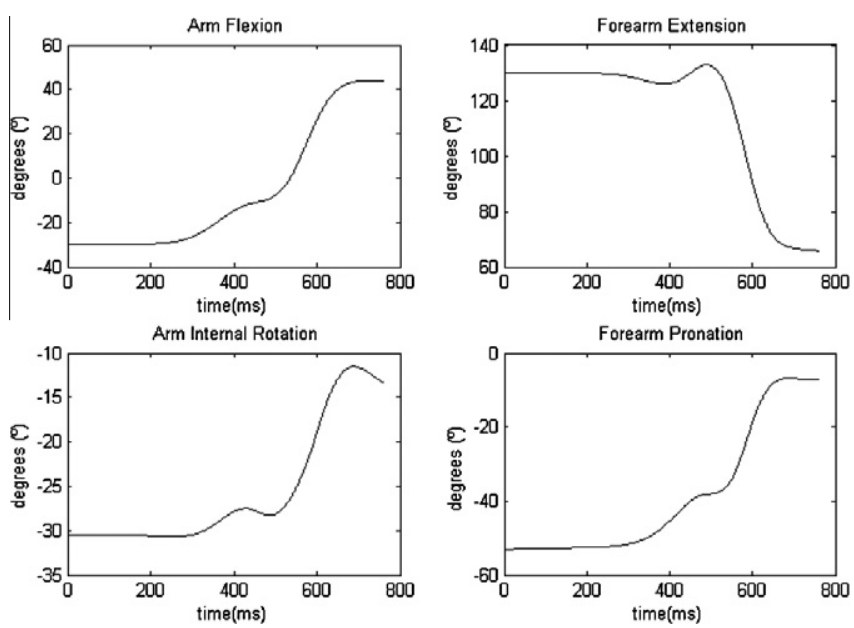

Fig. 3. Illustration of the positional curves of the arm and forearm movements of the choku-zuki execution.

its peak angular speed about $20 \mathrm{~ms}$ before contact. Arm internal rotation started from a position of external rotation of $-30^{\circ}$ and presented a mean range of about $18^{\circ}$, being in acceleration during $120 \mathrm{~ms}$ and reached the peak angular speed around $40 \mathrm{~ms}$ before contact. The final element to lead the fist toward the makiwara was the forearm extension, initially at $130^{\circ}$ of flexion, reaching the peak angular speed at approximately $30 \mathrm{~ms}$ before contact, with range about $60^{\circ}$.

In regards to group comparisons, significant differences between groups were obtained in several variables $(p<0.05)$. Specifically, in the time between the onset and the contact where in the karate group the arm flexion begins earlier and takes more time, and the forearm extension and pronation begins later and takes less time than in control group. Also the time in that was reached the peak angular speed of the forearm movements occurs more near at its end in the karate group than in the control group. Significant values were also found in the karate group where they have a larger peak angular speed of forearm pronation, and in the arm flexion they presented a significantly superior duration of angular acceleration.
In opposite to the karate group, the control group had a significantly larger duration of angular acceleration in the forearm pronation. This group also presents a significant large contact angle in the forearm pronation, and larger range movements inflexion and internal rotation of the arm, and in the forearm pronation (Table 2). No other significant difference between groups was attained in the other kinematic variables.

\subsection{EMG description and comparison}

Table 3 shows the EMG dependent variables of the karate and non-karate subjects, indicating the significant differences between groups.

The pattern sequence of muscles activation time in the karate group showed that the first muscles to be activated were the agonists of the arm flexion and internal rotation (DA, PC, and PS), about 250-260 ms before contact. This was followed by an initial activation of the forearm flexor and pronator muscles (BB1, BR1, and PT1), in about 262-247 ms. The forearm extensor muscle (TB) initiate its activity slightly later, at $153 \mathrm{~ms}$, followed by the second activation moment of forearm pronator muscle (PT2).

In the antagonistic muscles activity, on the arm internal rotation and flexion (IF, DP) it began $168 \mathrm{~ms}$ and $136 \mathrm{~ms}$ before contact, respectively, and approximately $100 \mathrm{~ms}$ lather then the agonist muscles activation. The antagonist muscles of the forearm extension and pronation (BB2, BR2) were the last ones to be activated.

Regarding peak of activity for the arm flexion and internal rotation muscles (DA, PC, and PS), it was reached around 80-95 ms before contact. However, in the antagonist muscles (IF, DP) itoccurred closer to the contact ( 45 and $25 \mathrm{~ms}$, respectively). In relation to the activation intensity of those movements, the agonist muscles (DA, PC, and PS) had a RMS between $85 \%$ and $100 \%$ of the IMVC, and the antagonists had a RMS about $70 \%$ of the IMVC in the IF muscle and a higher RMS in DP, about 130\% of the IMVC.

Considering the muscles acting in the forearm extension and pronation, the TB was clearly the one that had larger activation intensity, almost $100 \%$ of IMVC, but the PT muscle presented to a higher intensity of activity in its second activation. In the antagonist muscles (BB, BR), the intensity was less than 50\% of RMS of IMVC. 
Table 3

Average and standard deviation in the variables of muscle EMG in the execution of choku-zuki by karate (K) and non-karate subjects (NK).

\begin{tabular}{|c|c|c|c|c|c|c|c|}
\hline & & PC & PS & IF & DA & DP & TB \\
\hline \multirow[t]{2}{*}{ Onset muscles activation time } & K & $260 \pm 42$ & $247 \pm 26$ & $168 \pm 38$ & $263 \pm 43$ & $136 \pm 51$ & $153 \pm 40$ \\
\hline & NK & $259 \pm 28$ & $252 \pm 30$ & $173 \pm 55$ & $271 \pm 39$ & $138 \pm 64$ & $138 \pm 42$ \\
\hline \multirow[t]{2}{*}{ Offset muscles activation time } & $\mathrm{K}$ & $1 \pm 3$ & $0 \pm 2$ & $5 \pm 0$ & $0 \pm 2$ & $0 \pm 1$ & $1 \pm 3$ \\
\hline & NK & $6 \pm 21$ & $10 \pm 25^{\mathrm{a}}$ & $9 \pm 26$ & $0 \pm 1$ & $5 \pm 22$ & $1 \pm 2$ \\
\hline \multirow[t]{2}{*}{ Time of peak EMG } & $\mathrm{K}$ & $86 \pm 36$ & $95 \pm 32$ & $42 \pm 28$ & $82 \pm 31$ & $25 \pm 15$ & $32 \pm 21$ \\
\hline & NK & $106 \pm 27^{\mathrm{a}}$ & $115 \pm 32^{\mathrm{a}}$ & $47 \pm 30$ & $90 \pm 36$ & $36 \pm 22^{\mathrm{a}}$ & $38 \pm 20^{\mathrm{a}}$ \\
\hline \multirow[t]{3}{*}{ EMG root mean square (RMS) } & $\mathrm{K}$ & $100 \pm 83$ & $86 \pm 37$ & $71 \pm 17$ & $87 \pm 36$ & $132 \pm 53$ & $97 \pm 32$ \\
\hline & NK & $104 \pm 61$ & $107 \pm 62$ & $77 \pm 27$ & $79 \pm 58$ & $127 \pm 84$ & $88 \pm 36$ \\
\hline & & BB1 & BB2 & PT1 & PT2 & BR1 & BR2 \\
\hline \multirow[t]{2}{*}{ Onset muscles activation time } & $\mathrm{K}$ & $262 \pm 25$ & $86 \pm 29$ & $247 \pm 35$ & $98 \pm 35$ & $249 \pm 26$ & $90 \pm 33$ \\
\hline & NK & $25 \pm 50$ & $99 \pm 36$ & $225 \pm 72$ & $94 \pm 31$ & $248 \pm 52$ & $85 \pm 36$ \\
\hline \multirow[t]{2}{*}{ Offset muscles activation time } & K & $126 \pm 23$ & $0 \pm 0$ & $123 \pm 24$ & $0 \pm 0$ & $130 \pm 28$ & $0 \pm 0$ \\
\hline & NK & $113 \pm 34^{\mathrm{a}}$ & $0 \pm 0$ & $106 \pm 39^{a}$ & $0 \pm 0$ & $127 \pm 42$ & $0 \pm 0$ \\
\hline \multirow[t]{2}{*}{ Time of peak EMG } & $\mathrm{K}$ & $204 \pm 24$ & $21 \pm 19$ & $198 \pm 33$ & $19 \pm 16$ & $199 \pm 26$ & $19 \pm 15$ \\
\hline & NK & $200 \pm 47$ & $31 \pm 18$ & $184 \pm 72$ & $28 \pm 20^{a}$ & $201 \pm 39$ & $20 \pm 16$ \\
\hline \multirow[t]{2}{*}{ EMG root mean square (RMS) } & $\mathrm{K}$ & $35 \pm 21$ & $25 \pm 17$ & $45 \pm 20$ & $79 \pm 44$ & $50 \pm 21$ & $41 \pm 22$ \\
\hline & NK & $25 \pm 15^{\mathrm{a}}$ & $35 \pm 30$ & $52 \pm 58$ & $72 \pm 55$ & $41 \pm 24$ & $49 \pm 41$ \\
\hline
\end{tabular}

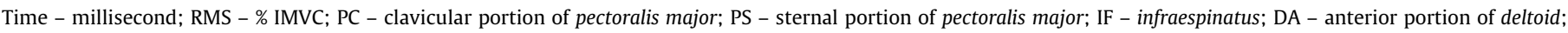
DP - posterior portion of deltoid; TB - lateral head of the triceps brachii; BB - biceps brachii; PT - pronator teres; BR - brachio radialis.

${ }^{a}$ Indicates statistically significant differences between groups $(p \leqslant .05)$.

Comparing the muscle activity between the groups, the EMG parameter with larger variation among them was the time of peak of activity, where the control group showed a significantly larger interval of time between the time of peak and contact in the arm muscles PC, PS, DP, and in forearm muscles TB and PT2.

Based on the value of RMS, we only found significant differences in the intensity of the first period of BB activation, which had a lower value on control group.

No significant differences were found between groups in the beginning time of the muscular activation were it tends to be similar between groups.

\section{Discussion}

\subsection{Karate punch description}

The aim of the study was to characterize the choku-zuki technique by the karate group. Our results demonstrate that they use a movement pattern with a sequence from proximal-to-distal, and that the arm movements reached its peak angular speed before the forearm movements.

The peak angular speed of the movements accomplished around the longitudinal axis of the segment (arm internal rotation and forearm pronation) occurred later than the movements executed around the lateral axis (arm flexion and forearm extension). Additionally, the forearm extension reached a greater peak angular speed than the arm flexion, suggesting some speed transference from the proximal limb to the distal during movement (Van Gheluwe and Hebbelink, 1985; Putnam, 1993; Hirashima et al., 2002). This could result in an increasing of speed and power on the punch execution. However, this behavior was not observed for arm internal rotation and forearm pronation.

The peak angular speed of each segmental movement finds correspondence in the time of muscle peak activity sequence. Therefore, muscular activation began with the flexion muscles and arm internal rotators which reached its peak before contact, and before the peak angular speed, respectively, of the arm flexion and internal rotation.

The antagonist muscles of the upper arm movements and the main responsible for the forearm extension presented its peak of activity prior to contact. Finally, in the last ms that preceded the time of contact the pronation muscle and the forearm extension antagonist muscles were activated, with its peak of activity to append near contact.

In the forearm movements a temporal coincidence was found between the time of peak angular speed and the time of peak of activity of the agonist muscles, probably due to the influence that the acceleration of the arm has in the acceleration of the forearm. Furthermore, the fact that we have not monitored the pronator quadratus muscle, due to the exclusively use of surface electrodes, may also explain this coincidence in the forearm pronation.

The first period of activation of the forearm flexion (BB1, BR1) and pronation (PT1) muscles must be responsible for the elbow stabilization, preparing the forearm to the following acceleration. These results are supported by Neto and Magini (2008) who shown that $\mathrm{BB}$ assists during arm flexion, and in agreement with the two activation periods of the BB, BR and PT, McGill et al. (2010) described the existence of a double peak of muscle activation in mixed martial arts fighters.

In what is concerned to the time of muscles activity, the coordination among agonist and antagonist muscles seems to obey to a phasic pattern of reciprocal enervation, similar to another ballistic movements (Desmedt and Godaux, 1979; Wadman et al., 1979; Le Bozec et al., 1980), but the period of co-contraction tends to be higher, superior to $100 \mathrm{~ms}$ for the arm muscles and $70 \mathrm{~ms}$ for the forearm muscles, than was verified in those studies. These could reflect the necessity of high precision to punch the makiwara.

Analyzing the normalized value of mean RMS, surprisingly, the muscle that presented higher activation intensity was the DP, showing the importance of slowing down the arm flexion movement as a protective mechanism on the involved joint (Wilk et al., 1997). Accordingly, Sbriccoli et al. (2010) found that elite karatekas possessed high level of antagonist activation during the execution of a front kick. This higher DP activation, in this skill, results in transfer of acceleration and velocity to the distal segment caused by proximal segment deceleration and this could increment the punch power. But this high activation could be related to with the shoulder joint protection.

The high activation in the agonist muscles of arm flexion and internal rotation reveals its role in limb acceleration, as well as the transfer of energy to the forearm extension, where the TB achieved a similar activation. Witte et al. (2005) found to a high TB activation during the execution of a karate punch technique as well as Neto and 
Magini (2008) in a Kung Fu strike. Also, Dinn and Behm (2007) found a significant increase in the pectoralis major and TB activation, after dynamic and isometric punch training, respectively.

The IF, besides being antagonist of the arm internal rotation, was involved in the dynamic stability of the glenohumeral joint, what is important to all movement of punch. The forearm pronation muscle presented a little less intense activation, but higher than the forearm flexors who are only involved in controlling the forearm moments.

\subsection{Comparison between groups}

It is assumed that karate training alters motor control strategies promoting the improvement of performance. The appropriate motor actions of the task to develop are the acquisition, improvement and stabilization of neuromuscular coordination patterns that translate into differences in kinematic motion characteristics. Thus, it was our expectation at the beginning of the current work that by comparing a karate group with a control group resulted in significantly different kinematic and EMG parameters, and our aim was to identify what distinguishes a karate athlete (expert) from a non karate athlete in the execution of the choku-zuki punch.

The literature reported an improvement of neuromuscular activation during a complex motor skill associated with higher upper limb velocity and punch impulse (Cesari and Bertucco, 2008), higher isokinetic knee torque suggesting a improvement in the recruitment of motor units (Sbriccoli et al., 2010) on karate athletes comparing with novice, as well as in kung fu where experienced practitioners present smaller antagonist muscular activity in the palm strike (Neto and Magini, 2008). Superior anticipatory skills (Mori et al., 2002), and a faster visuoperceptual speed (Kim and Petrakis, 1998) also arise from the comparison between different skill levels. Furthermore, a comparison of techniques has also been studied (Sforza et al. 2000; Gulledge and Dapena, 2008), as the force at impact (Girodet et al., 2005).

In the present study the control group began and reached the peak angular speed of the forearm movements significantly earlier; nevertheless, they presented the same proximal-to-distal sequence in the movements done in the sagittal plane. However, the movements produced around the longitudinal axis obeyed a different logic than it had been verified in the karate group, and is empirical described by the karate masters.

The significant anticipation of the forearm pronation time of peak angular speed in control group could probably be related with the lower value of peak angular speed comparing to karate group. This lower speed allows them to position the fist for the contact earlier, which could be associated with a defensive and protecting action of the anatomical structures against the contact with the makiwara, but with a more slowly movement the power in contact must be less in this group.

In fact, forearm pronation was the movement where we found more differences between groups. Besides the larger value of angular speed, the karate group reached its peak angular speed closer to contact than the control group, with smaller movement's range and duration and with smaller pronation degree in the contact time. This must be related with a more consolidated skill execution and less fear in punch the target and may increase the contact power in the punch.

The smaller movement range and duration in karate group are in agreement with the tendency referred in the literature as kinematic patterns were modified during learning of different motor tasks (Hobart et al., 1978; Jaegers et al., 1989; Pezarat-Correia et al., 2001).

The karate group showed muscle peak activity closer to contact at all agonist muscles of the arm and forearm. Hence, only differences in the temporary structures of the EMG activation were found between groups, but not in the activation intensity of the studied muscles. These temporary differences in the EMG are the reason of the kinematic alterations between groups and must be responsible for a faster and strongly skill execution in karate athletes' Correspondingly, Liang et al. (2008) reported that the improvement in ballistic performance was mainly due to the temporal modulations of agonist and antagonist muscle activities.

This study brings the kinesiology basis of a punch fundamental in the karate learning process, done by experienced athletes. This could be important information to the trainers, but the information about the neuromuscular control pattern could be important in further investigation. The study was limited to experts and non-karate subjects, who bring us the interrogation if the middle level karate subjects have the same characteristics, and if man and women are different on this skill execution. Those are some of many questions to be answered in future works.

In conclusion, the karate group showed a better ballistic performance in the execution of the choku-zuki punch, through the peak angular speed and peak EMG closer to contact, and a tendency to lower movement's range and duration who could report more power in contact.

\section{References}

Basmajian JV, De Luca CJ. Muscles alive. Their functions revealed by Electromyography. Baltimore: William \& Wilkins; 1985.

Bledsoe GH, Hsu EB, Grabowski JG, Brill JD, Li G. Incidence of injury in professional mixed martial arts competitions. Sports Sci Med 2006:136-42.

Cesari P, Bertucco M. Coupling between punch efficacy and body stability for elite karate. J Sci Med Sport 2008;11(3):353-6.

Corcos DM, Gottlieb GL, Jaric S, Cromwell RL, Agarwal GC. Organizing principles underlying skill acquisition. In: Winters JM, Woo SL, editors. Multiple Muscle Systems. Biomechanics and Movement Organization. New York: SpringerVerlag; 1990. p. 251-67.

Courtonne C. Physique etKaraté. Le secret de la puissance. Paris: Editions Chiron; 1996.

Desmedt JE, Godaux E. Voluntary motor commands in human ballistic movements Ann Neurol 1979:5(5):415-21.

Dinn NA, Behm DG. A comparison of ballistic-movement and ballistic-intent training on muscle strength and activation. Int J Sports Physiol Perform 2007;2(4):386-99.

Engelhorn R. Agonist and antagonist muscle EMG activity pattern changes with skill acquisition. Res Q Ex Sport 1983;54(4):315-23.

Giakas G, Baltzopoulos V. A comparison of automatic filtering techniques applied to biomechanical walking data. J Biomech 1997;30(8):847-50.

Girodet P, Vaslin P, Dabonneville M, Lacouture P. Two-dimensional kinematic and dynamic analysis of a karate straight punch. Comput Methods Biomech Biomed Engin 2005;8(1):117-8.

Gulledge JK, Dapena J. A comparison of the reverse and power punches in oriental martial arts. J Sports Sci 2008;26(2):189-96.

Hallett M, Shahani BT, Young RR. EMG analysis of stereotyped voluntary movements in man. J Neurol Neurosurg Psychiatry 1975;38(12):1154-62.

Hirashima M, Kadota H, Sakurai S, Kudo K, Ohtsuki T. Sequential muscle activity and its functional role in the upper extremity and trunk during overarm throwing. J Sports Sci 2002;20(4):301-10.

Hobart DJ, Vorro JR, Dotson CO. Synchronized myoelectric and cinematographic analysis of skill acquisition. J Human Mov Stud 1978;4:155-66.

Hodges PW, Bui BH. A comparison of computer-based methods for determination of onset of muscle contraction using electromyography. Electroencephalogr. Clin. Neurophysiol 1996;101(6):511-9.

Jaegers S, Peterson R, Dantuma R, Hillen H, Geuze R, Schellekens J. Kinesiologic aspects of motor learning in dart throwing. J Hum Mov Stud 1989;16:161-71.

Kim HS, Petrakis E. Visuoperceptual speed of karate practitioners at three levels of skill. Percept Mot Skills 1998;87(1):96-8.

Le Bozec S, Maton B, Cnockaert JC. The synergy of elbow extensor muscles during dynamic work in man: I. Elbow extension. Eur J Appl Physiol Occup Physiol 1980;44(3):255-69.

Liang N, Yamashita T, Ni Z, Takahashi M, Murakami T, Yahagi S, et al. Temporal modulation of agonist and antagonist muscle activities accompanying improved performance of ballistic movements. Hum Mov Sci 2008;27(1):12-28.

Link N, Chou L. The Anatomy of Martial Arts, an Illustrated Guide to the Muscles used in key Kicks, Strikes \& Throws. Ulysses Press; 2011.

McGill SM, Chaimberg JD, Frost DM, Fenwick CM. Evidence of a double peak in muscle activation to enhance strike speed and force. An example with elite mixed martial arts fighters. J Strength Cond Res 2010;24(2):348-57.

Meskers CGM, Helm FCTvd, Rozendaal LA, Rozing PM. In vivo estimation of glenohumeral joint rotation center from scapular bony landmarks by linear regression. J Biomech 1998;31:93-6. 
Meskers CGM, Fraterman H, Helm FCTvd, Vermeulen HM, Rozing PM. Calibration of the "Flock of Birds" electromagnetic tracking device and its application in shoulder motion studies. J Biomech 1999;32(6):629-33.

Micera S, Sabatini AM, Dario P. An algorithm for detecting contraction by EMG signal processing. Med Eng Phys 1998;20(3):211-5.

Miyashita M, Tsunoda T, Sakurai S, Nishizono H, Mizuno T. Muscular activities in the tennis serve and overhand throwing. Scand J Sports Sci 1980;2(2):52-8.

Mori S, Ohtani Y, Imanaka K. Reaction times and anticipatory skills of karate athletes. Hum Mov Sci 2002;21(2):213-30.

Nakayama M. Dynamic Karate: Instruction by the Master. Tokyo: Kodansha International LTD; 1983.

Neto OP, Magini M. Electromiographic and kinematic characteristics of Kung Fu Yau-Man palm strike. J Electromyogr Kinesiol 2008;18(6):1047-52.

Pezarat-Correia P, Santos P, Veloso A, Cabri J. Differences in the agonist/antagonist EMG pattern during a throwing task performed by experimented dart throwers and untrained subjects. Med Sci Sports Exerc 2001;33(5):S216.

Putnam CA. Sequential motions of body segments in striking and throwing skills: descriptions and explanations. J Biomech 1993;26(1):125-35.

Roetenberg D, Buurke JH, Veltink PH, FornerCordero A, Hermens HJ. Surface electromyography analysis for variable gait. Gait Posture 2003;18(2):109-17.

Sanes JN, Jennings VA. Centrally programmed patterns of muscle activity in voluntary motor behaviour of humans. Exp Brain Res 1984;54(1):23-32.

Sbriccoli P, Camomilla V, Di Mario A, Quinzi F, Figura F, Felici F. Neuromuscular control adaptations in elite athletes: the case of top level karateka. Eur J Appl Physiol 2010;108(6):1269-80.

Schmidt RA, Wrisberg CA. Motor learning and performance. A problem-based learning approach. 2nd ed. Champaign, IL: Human Kinetics Publishers; 2000.

Sforza C, Turci M, Grassi G, Fragnito N, Pizzini G, Ferrario VF. The repeatability of choku-tsuki and oi-tsuki in traditional Shotokan karate: a morphological threedimensional analysis. Percept Mot Skills 2000;90(3):947-60.

Van Gheluwe B, Hebbelink M. The kinematics of the service movement in tennis: A three-dimensional cinematographical approach. In: Winter D, Norman R, Wells R, Hayes K, Patla A, (eds.), Biomechanics IX-B. Champaign: Human Kinetics Publishers Inc, 1985:521-6.

Veeger HEJ. The position of the rotation center of glenohumeral joint. J Biomech 2000;33(12):1711-5.

Wadman W, Denier van der JJ, Geuze RH, Mol CR. Control of fast goal-directed arm movements. J Hum Mov Stud 1979;5:3-17.

Wilk KE, Arrigo CA, Andrews JR. Current concepts: the stabilizing structures of the glenohumeral joint. J Orthop Sports Phys Ther 1997;25(6):364-79.

Witte K, Emmermacher P, Hofmann M, Schwab K, Witte H. Electromyographic researches of gyaku-zuki in karate kumite. In: Wang $Q$ (ed.), Proceedings of XXIII International Symposium on Biomechanics in Sports. Beijing, China: The People Sport Press, 2005:861-65.

Ying N, Kim W. Use of dual Euler angles to quantify the three-dimensional joint motion and its application to the ankle joint complex. J Biomech 2002;35(12):1647-57.

Zetaruk MN, Violan MA, Zurakowski D, Micheli LJ. Karate injuries in children and adolescents. Br J Sports Med 2005;39:29-33.

Zetaruk MN, Violan MA, Zurakowski D, Micheli LJ. Karate injuries in children and adolescents. Accident Analysis and Prevention 2000;32:421-5.

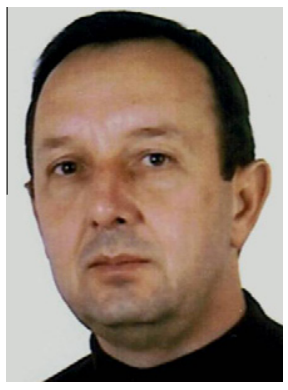

António M. Vences Brito, born in 1961, obtained the Bc degree in Radiology from the School of Technology of the Health, Lisbon, in 1987, the Bc in Sport Sciences from the Faculty of Human Kinetics, Technical University of Lisbon, in 1995, the M.Sc. in High Performance Training from the Faculty of Human Kinetics, Technical University of Lisbon in 2001, and obtained the Ph.D. degree in Human Kinetics in the specialty of Motricity Sciences, from the Faculty of Human Kinetics, Technical University of Lisbon, Portugal, in 2009. He is full Professor in Anatomophysiology in the Sports Sciences School of Rio Maior and in Agrarian School of Santarém, Polytechnic Institute of Santarém, Portugal. He is researcher of the Investigation Center in Sport, Human Health and Development (CIDESD), member of the European College of Sport Sciences and of the International Martial Arts and Combat Sports Scientific Society where he is co-responsible for the division of kinesiology. His research focuses on neural control and coordination of the muscles activity and in sport physiology. Within these areas, he has (co)-authored several papers in peer-reviewed Journals and in conference papers/abstracts.

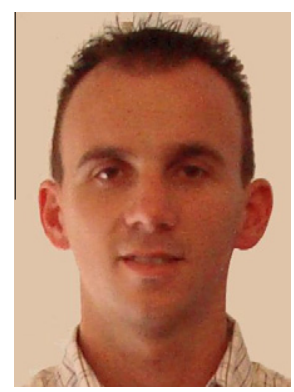

Mário André Rodrigues Ferreira, BSp and BPhEd, was born in 1984. He obtained the Bachelor degree in Sport at the Sport Sciences School of Rio Maior, Polytechnic Institute of Santarém in 2007, and the Bachelor degree in Physical Education at the Faculty of Sport Sciences and Physical Education of the University of Coimbra in 2009. He is currently a Ph.D. student in Sport Sciences at the University of Madeira and Sport Sciences School of Rio Maior, Polytechnic Institute of Santarém. He is member of the European College of Sport Sciences since 2008. His main research interests are motor control and learning, neuromuscular activation in sport-specific motor skills, exercise and sport physiology.

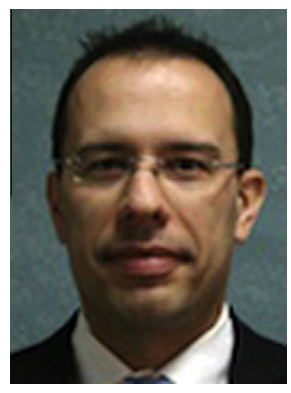

Nelson Cortes earned a Bachelor of Science in Physical Education \& Exercise Science from Universidade Lusofona de Humanidades e Tecnologias in Lisbon, Portugal, with a special emphasis in Sports Biomechanics. Later, he obtained a M.S. Ed. in Exercise Science with concentration in Clinical Biomechanics; and his Ph.D. in Human Movement Science from Old Dominion University. Dr. Cortes is an Assistant Professor in Kinesiology in the School of Recreation, Health, and Tourism and affiliated with the Sports Medicine Assessment, Research and Testing (SMART) Laboratory at George Mason University, Fairfax VA. His research focus on biomechanical analysis of human movement specifically related to lower extremity injury prevention. He is highly interested in developing patient-specific models to further understand predictive factors for injury. Within these areas, he has (co)authored several papers in peer-reviewed Journals and in conference papers/ abstracts.

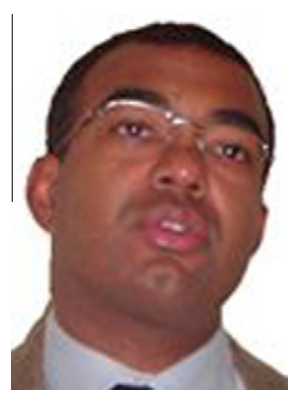

Orlando J.S.M. Fernandes. Is graduated in Sports Science - Master in Sport Science, Ph.D. in Sport Science. Currently is Assistant Professor of the University of Évora where teaches Biomechanics and Movement Analysis. Research topics: Sports Biomechanics, Motor Control and neuromuscular function.

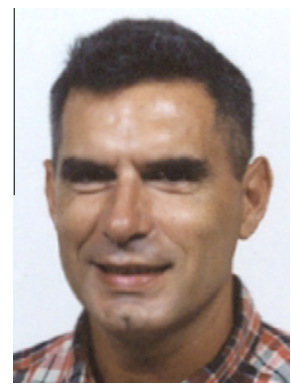

Pedro Pezarat-Correia, born in 1958, is graduated in Physical Education, Ph.D. in Human Kinetics (Faculty of Human Kinetics of the Technical University of Lisbon Portugal) in 1995. Currently is Associated Professor of the Technical University of Lisbon where teaches disciplines of Anatomophysiology, Kinesiology and Neuromuscular Function in graduate and post-graduate courses. He is researcher of the Laboratory of Motor Behaviour from the Faculty of Human Kinetics. Research topics: electromyography, kinesiology, neuromuscular function, motor control. 